\title{
Cleaning Up Company Data
}

NEW XBRL VALIDATION RULES COULD IMPROVE DATA QUALITY

By Mohini Singh, ACA

CFA Institute has long supported companies' use of structured data, in particular XBRL (eXtensible Business Reporting Language). Structured data provides a standardized, interactive, computer-based framework for financial reporting and financial statement generation. Key benefits include increased efficiency, transparency, comparability, and timeliness in the delivery of financial information to all parties in the information supply chain. In other words, structured data can allow for the "democratization" of financial information.

As with other technologies, we are experiencing growing pains in the implementation of XBRL. Chief amongst the challenges is data quality, which affects the automated analysis of XBRL data. One of the biggest data quality challenges is the unnecessary use of extensions. The XBRL taxonomy associated with the US generally accepted accounting principles (GAAP) has many thousands of data elements from which a company may select. This situation has led companies to tag similar or comparable items differently. Other data quality issues include scaling (i.e., determining the number of digits used in the data) and input errors, including incorrect use of negative values.

So, although every US public company provides financial information using XBRL to the Securities and Exchange Commission (SEC), automated analysis of financial data using XBRL data has been limited because analysts and investors are concerned about the accuracy, consistency, and reliability of the data.

To address this challenge, XBRL US partnered with several filing agencies and the American Institute of CPAs to create the Center for Data Quality. The initiative is directed by the Data

\section{ONE OF THE BIGGEST DATA QUALITY CHALLENGES IS THE UNNECESSARY USE OF EXTENSIONS. THIS SITUATION HAS LED COMPANIES TO TAG SIMILAR OR COMPARABLE ITEMS DIFFERENTLY.}

Quality Committee (DQC), which membership includes software providers, data aggregators, institutional investors, accounting professionals, and academics. Along with CFA Institute, other user-focused organizations such as Bloomberg, Calcbench, S\&P Capital IQ, and Credit Suisse HOLT have a seat at the table.

The DQC (which oversees the development of guidance and rules intended to remove inconsistencies from XBRL reports and serves as a resource for the SEC and the Financial Accounting Standards Board) recently finalized its first set of rules. These items are intended to clean up reporting practices on a range of straightforward topics such as the tagging of dates, inappropriate use of negative values, and defining clear relationships between certain taxonomy elements.

We encourage companies to follow the validation rules to clean up the errors and inconsistencies we currently see in XBRL reports.

Mohini Singh is director of financial reporting policy at CFA Institute.

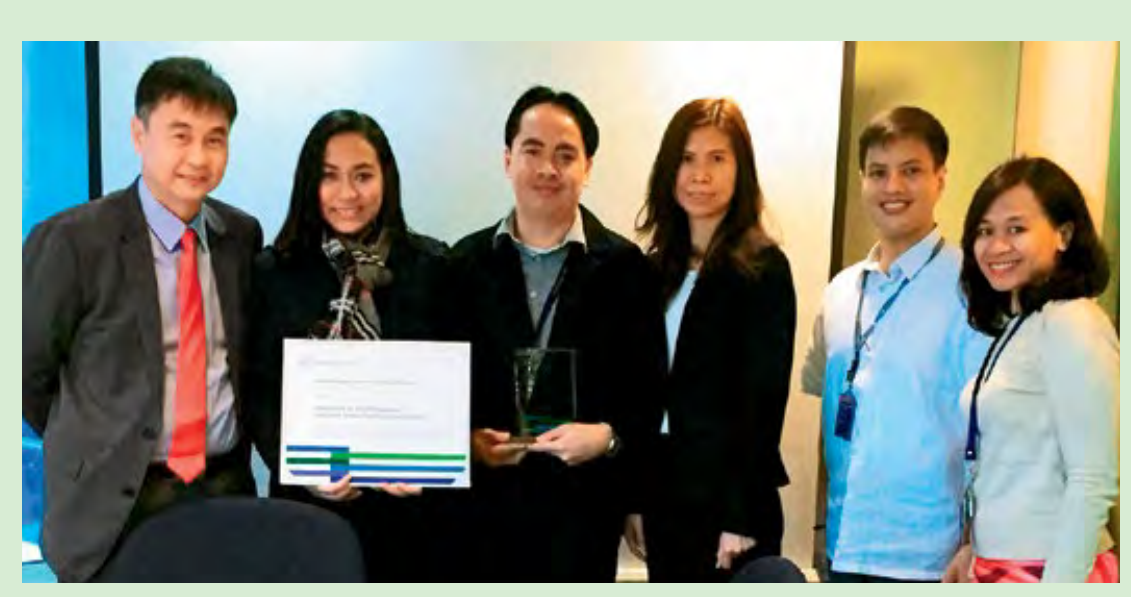

UnionBank Trust and Investment Services Group is the first firm from the Philippines trust sector to comply with the CFA Institute Asset Manager Code of Professional Conduct. CFA Institute staff recently met with representatives from the firm to discuss the benefits of the Asset Manager Code and to present a certificate recognizing the firm's compliance. They also discussed possible adoption of the Global Investment Performance Standards (GIPS $₫$ ). Participating in the meeting were Tony Tan, DBA, CFA, head of Standards and Advocacy at CFA Institute for the Asia Pacific region; Jay-Ann Canong, trust risk and compliance officer at UnionBank; Kim Unidad, trust risk and compliance manager at UnionBank; Irene Cheung, CFA, CAIA, FRM, director of standards of practice at CFA Institute for the Asia Pacific region; Robert Ramos, CFA, trust group head at UnionBank; and Joy Sampedro, trust business development head at UnionBank. 